КАМИНСКАЯ Татьяна Леонидовна - доктор филологических наук, доцент; профессор департамента политологии и массовых коммуникаций Финансового университета при Правительстве РФ (125993, г. Москва, ГСП-3, Ленинградский np-кm, 49; tlkam1@таil.ru)

ЧАУСОВ Александр Игоревич - кандидат исторических наук, доцент; доцент кафедры журналистики Новгородского государственного университета им. Ярослава Мудрого (173003, Россия, г. Великий Новгород, ул. Санкт-Петербургская, 41; aleshausov@таil.ru)

\title{
НАЦИОНАЛЬНЫЕ ПРОЕКТЫ И МЕДИАСФЕРА: ПРОДВИЖЕНИЕ И ВОСПРИЯТИЕ
}

Аннотация. Статья представляет итоги мониторинга информации, касающейся национальных проектов России в русскоязычной медиасфере: в информационных проектах власти, в ведущих СМИ, социальных сетях и мессенджерах, в новых медийных форматах. Актуальность исследования связана с тем, что от восприятия населением планов власти и его вовлеченности в контроль и обсуждение их исполнения во многом зависит реализация национальных проектов. Использование популярных среди различных целевых аудиторий медиаформатов для донесения позитивной повестки власти представляется неэффективным и неравномерным по отношению к нацпроектам.

Ключевые слова: национальные проекты, медиа, целевая аудитория, социальные сети, новые медиаформаты

$\Pi$ оявление масштабных проектов в середине 2010-х гг. воспринималось населением с большим интересом. Это связано с ностальгией у общества, пережившего турбулентные 1990-е гг., по масштабным планам развития и устремленности в позитивное будущее. До кризиса 2008 г. при росте ВВП продвигать позитивную повестку власти посредством медиа было достаточно легко.

Проблемы дальнейшего продвижения связаны со снижением темпов реализации проектов. Здесь сыграли роль как финансовые кризисы (2008-2009, 2014, 2020 гг.), санкции, так и бюрократизация самих проектов. Кроме того, информационное сопровождение и восприятие проектов населением усложнилось тем, что из временных и точечных они превратились в постоянные и масштабные, и в сознании людей перемешались с базовым функционалом профильных министерств и партийными проектами «Единой России». Однако, подводя итоги развития страны за последнее десятилетие, ученые возлагают надежды именно на проектное управление, которое «позволяет обеспечить концентрацию и рациональное использование ограниченных ресурсов (финансовых, инвестиционных, человеческих, управленческих и др.)» [Кожевников 2020: 69].

Текущий момент представляется поворотным моментом для трансформации всей системы информационного и организационного сопровождения нацпроектов, необходимость которой подогревается коммуникативными практиками во время пандемии. Рассмотрим ведущие существующие каналы продвижения нацпроектов в новой медийной реальности.

Следует сразу заметить, что все масштабные медиапроекты, созданные под эгидой власти, отличаются, как правило, однонаправленной коммуникацией и отсутствием прямого вовлечения пользователей в обсуждение и соучастие в создании контента, но при этом имеют ряд неоспоримых плюсов.

1. Несомненным позитивным моментом информационного портала «Будущее России. Национальные проекты» ${ }^{1}$, оператором которого выступает ТАСС, является простая и доступная для понимания инфографика - визуализация не

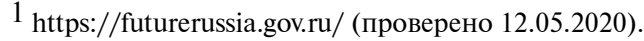


только статистических показателей, но и лиц, персонально ответственных за реализацию нацпроектов.

2. Первый видеоблог «Время, вперед!»1, посвященный достижениям современной России, выходящий на ҮouТube каждое воскресенье (за редким исключением) с 2012 г., использует современные тренды визуализации, новые мультимедийные технологии и при предъявлении позитивной повестки имеет хороший аудиторный показатель (213 тыс. подписчиков). Ресурс справедливо декларирует, что демонстрирует новости, «на которые другие СМИ не любят обращать внимание». То, что СМИ «не любят хорошие новости», авторы видеоблога объясняют тем, что их «трудно «продать», а «аудиторию приучили к потреблению негатива». Действительно, дискурс позитивных изменений, тем более информация о ежедневной рутине: зарплатах, дорогах, детских садах и школах, а также заводах-самолетах-атомоходах и воспринимается, и создается с бо́льшими сложностями, чем ужасы про катаклизмы и коррупцию.

3. К достоинствам проекта на сайте «Российской газеты» относится представление ситуации по нацпроектам из регионов ${ }^{2}$. И действительно, идея о продвижении нацпроектов в режиме нон-стоп и с привлечением региональной повестки - самая продуктивная. Однако тут возникает другая проблема: федеральные СМИ не приветствуют региональную повестку, а реализация нацпроектов - это и есть конкретные километры дорог местного значения, конкретные поликлиники и ФАПы в условном городе.

При этом федеральные медиа, традиционно входящие в топ-10 по версии Медиалогии ${ }^{3}$, такие как «Коммерсантъ», «Новая газета», «Эхо Москвы», выдают в поиске по ключевым словам от 500 до 1000 публикаций, связанных с нацпроектами, за последний год. Контент-анализ публикаций показывает, что ньюсмейкерами чаще всего в них выступают высокопоставленные официальные лица, а жанр их - преимущественно новости об освоении средств, форумах, перестановках во власти. Таким образом, приближенность контента нацпроектов к реальным запросам населения на местах крайне мала.

При этом поиск с помощью любых новостных агрегаторов из общего онлайнмедиаконтента (не только зарегистрированные СМИ) выдает как самое частотное слово, связанное со словом «нацпроект», - слово «распил». Массовое недоверие к освоению средств иллюстрируют и популярные мемы на темы нацпроектов, ведущие концепты которых «деньги», «неудачи», «обман» ${ }^{4}$. То, что мемы являются важной частью политической коммуникации, не раз подтверждалось современными исследователями различных стран и политическими решениями. Приводя примеры таковых, С.А. Шомова указывает, что мем представляет собой «реальный идеологический, пропагандистский инструмент, осознанную технологию политического влияния. В очередной раз это зримо продемонстрировали президентские выборы в России 2018 г., в коммуникативной составляющей которых обнаруживаются определенные отличия от всех предыдущих выборных кампаний [Шомова 2019: 158]. Понятно, что создать популярные мемы по заданию нельзя, и алгоритм популярности мема до сих пор не существует, однако пренебрегать такой практикой коммуникации с населением при продвижении национальных проектов - непродуктивно.

Как недостаток продвижения следует отметить отсутствие какого-либо упо-

\footnotetext{
1 https://www.youtube.com/user/ShkolaFaberlic (проверено 12.05.2020).

2 https://rg.ru/sujet/6234/ (проверено 12.05.2020).

3 https://www.mlg.ru/ratings/media/federal/ (проверено 13.05.2020).

4 https://go.mail.ru/search_images?fm=1\&rf=https\%253A\%252F\%252Fe.mail.ru\%252F\&q=\%D0\%BC\% D0\%B5\%D0\%BC\%D1\%8B\%20\%D0\%BD\%D0\%B0\%D1\%86\%D0\%BF\%D1\%80\%D0\%BE\%D0\%B5\%D0 $\%$ BA\%D1\%82\%D1\%8B\&frm=web (проверено 13.05.2020).
} 
минания о целях и ходе национальных проектов на популярных политических или специализированных онлайн-медиаресурсах. Дело в том, что специализированные ресурсы обладают влиянием на узкие целевые аудитории по интересам, и на них эффективно продвигать отдельные проекты. Так, например, нацпроект «Наука» мог бы быть интересен целевой аудитории раздела PRO SCIENCE сайта Полит.ру ${ }^{1}$ или в различных форматах проекта Постнаука.ру ${ }^{2}$, аудитория которых исчисляется в сотнях тысяч. Кстати сказать, вовлечение российского научного сообщества в обсуждение, исследование хода реализации нацпроектов и реакции населения крайне мало́. Научные публикации (более 300 за последние 3 года, по данным базы РИНЦ) по исследованиям в сферах статистики и законодательства не входят в поле зрения широкой общественности и власти, не актуализируются в публичном дискурсе.

Особенно следует подчеркнуть недостаточное использование социальных сетей и мессенджеров в информационной работе по нацпроектам. В социальной сети ВКонтакте, например, по ключевым словам «национальные проекты», «нацпроекты» можно найти всего не более десятка сообществ - как относительно многочисленных (например, «Нацпроекты глазами родителей» -23 тыс. подписчиков $)^{3}$, так и региональных - с несколькими сотнями участников ${ }^{4}$. При этом контент этих групп однотипен и предсказуем (от поздравлений власти с праздниками до информационных сообщений о строительстве объектов).

Только изредка можно увидеть в социальных сетях отдельные интересные сообщения и инициативы по нацпроектам. В частности, в Инстаграме анонсировано создание нового журнала «Будущее России. Национальные проекты» 5 .

\section{Новые медийные роботизированные платформы \\ и продвижение нацпроектов}

В отношении новых платформ следует назвать прежде всего 3 платформы, получившие особую популярность в России в последние 2 года и влияющие на политическую и социальную ориентацию, прежде всего молодежи. Это Яндекс. Дзен, Тик.Ток и мессенджер Телеграм. Что касается молодежной аудитории, то отсутствие интереса у большинства представителей к политическим темам в онлайне не раз подчеркивалось масштабными исследованиями медиапредпочтений и медиаактивности молодежи [Домбровская, Пырма, Батанина 2019].

Поэтому не случайно в Дзене практически полностью отсутствует достоверная информация по нацпроектам с какими-то экспертными и статистическими данными, особенно у молодых авторов каналов. Однако зачастую тема нацпроектов представлена трактовками их как угрожающих привычной жизни, масонскими планами власти. Вот характерный пример предъявления этой тематической повестки (пунктуация автора сохранена): «Прямо сейчас, когда нас умело отвлекли всемирной пандемией, реализуются многомиллиардные национальные проекты. Есть люди, кто хотят от нас получить все личные данные, хотят чтоб мы были максимально понятны им, хотят чтоб мы были управляемы и хотят прогнозировать свой бизнес, то есть понимать, что такое нужно сделать для нас, чтоб мы купили, проголосовали, легли спать, пошли на работу, хотят манипулировать нашим сознанием и хотят воспитать из наших детей поколение потребителей и рабов... Поэтому этой статьей я призываю Вас

\footnotetext{
1 https://polit.ru/rubric/proscience/ (проверено 13.05.2020).

2 https://postnauka.ru/ (проверено 15.05.2020).

3 https://vk.com/public184623434 (проверено 13.05.2020).

4 https://vk.com/np29novodvinsk (проверено 13.05.2020).

5 https://www.instagram.com/p/B-_Z_MTjOu8/?igshid=166v12jo66xgw (проверено 12.05.2020).
} 
каждого прочитать о национальном проекте “Образование”, который реализуется уже сейчас, прочитали про цифровую образовательную среду. Да, нам не говорят об этом в СМИ, многие даже не подозревают, что сейчас происходит и к чему все это может привести, потому что это невыгодно крупным “игрокам" нашего мира. Мой муж юрист и в силу свои профессиональных связей, мы знаем чуть больше, чем большинство, поэтому я пишу об этом, хочу, чтоб как можно больше простых людей, таких как мы, тоже [знали]»1.

С нашей точки зрения, необходимо наладить предоставление информации по нацпроектам на Яндекс.Дзене путем создания авторских каналов, приняв во внимание следующие моменты.

1. По сравнению со многими прочими платформами политика и алгоритмы Яндекс.Дзена направлены на обеспечение максимальных показов авторского взгляда, исходя из схожих интересов пользователей по предлагаемой теме. Важно и то, что использование данной платформы является бесплатным.

2. Число пользователей платформы постоянно увеличивается, что делает возможность монетизации канала все более вероятной.

3. Показы данной платформы присутствуют практически во всех сервисах Яндекса. Данное свойство позволяет получать максимальный приток показов и дочитываний на авторском канале.

4. Появляется возможность практически неограниченного размещения ссылок на другие ресурсы автора, что в итоге только увеличивает популярность использования авторами данной платформы и возможности продвижения, a также позволяет привлекать дополнительную аудиторию на другие ресурсы.

5. Отсутствие ограничения на объем авторских статей позволяет выдать максимум полезного контента.

Другая популярная платформа отличается от Дзена не только информационными форматами, но и аудиторией. Если в Дзене более половины аудитории - люди старше 45 лет, то здесь в основном находится молодежь (от средних классов школы до первых курсов вузов). Это TikTok, который стал популярным из-за коротких, быстрых видео, легких для восприятия: их просмотр затягивает учащуюся молодежь (в мире - более 500 млн, а в России - 8 млн пользователей). При этом видео можно выбрать по интересам. Немногочисленные исследования данного феномена связаны именно с аудиторным фактором и подчеркивают его популярность среди молодежи. Отмечается, что «прежде всего пользователи выбирают TikTok для того, чтобы находить развлекательный контент (59\%) и заполнять свободное время (53\%). Возможность делиться своими видео с другими пользователями лишь на третьем месте (30\%)» [Епишкин, Исакова, Лаврик 2019: 65].

Феномен Телеграма интересен, прежде всего, параллельной реальностью, которую создали авторы каналов в мессенджере (преимущественно анонимные). Статистика (РБК и Mediascope) демонстрирует увеличение числа ежедневных пользователей в 2019 г. на $31 \%$, что исследователи связали с эффектом Стрейзанд - феноменом, при котором попытка удалить информацию (блокировка канала Роскомнадзором) приводит к росту ее популярности. Сегодня российская аудитория приложения, по данным TGStat, составляет более 15 млн чел. Телеграм стал заметным инструментом влияния на общественное мнение. Основным читателем телеграм-каналов остается молодежь: возрастные группы $18-24$ года (27\%) и 25-34 года (38\%) суммарно составляют более половины всей

1 https://zen.yandex.ru/media/id/5d9329abd7859b00b1182ad8/seichas-realizuiutsia-mnogo-milliardnyenacionalnye-proekty-o-kotoryh-mnogie-daje-ne-znaiut-5eb6367ff2aa0073ed976eb5 (проверено 15.05.2020). 
опрошенной аудитории мессенджера ${ }^{1}$. По меткому замечанию главы ВЦИОМа Валерия Федорова, «телеграм-каналы заменили россиянам советские кухни» ${ }^{2}$.

В отношении продвижения нацпроектов следует отметить отсутствие в Телеграме популярных каналов с позитивной повесткой. Показательный пример: телеграм-канал «Национальные проекты. Комитет АМПР» имеет всего 50 подписчиков, телеграм-канал «Нацпроектный ревизор» - 873 подписчика. Все, что пишут в Телеграме о нацпроектах, можно прочитать в канале НАЦПРОЕКТЫ (1,4 тыс. подписчиков), который работает по принципу новостного агрегатора, собирая контент со словом «нацпроекты» (преимущественно из таких, как Незыгарь, Зеленый змий и подобных «раскрученных» каналов). Кстати сказать, наиболее активно в мессенджерах обсуждают нацпроект «Экология» за счет беспрецедентной коммуникативной активности экологических активистов. Об эффективности медиапродвижения экологической повестки в России писалось ранее [Каминская, Помигуев, Назарова 2019].

И хоть по масштабу просмотров и подписок мессенджер в разы уступает Яндекс.Дзену, но в совокупности своих каналов по влиянию на умы сопоставим с любым популярным медиа. Вообще научного осмысления феноменов указанных новых платформ крайне мало, в базе РИНЦ на начало 2020 г. содержатся не более двух десятков публикаций об их особенностях.

\section{Пандемия COVID-19 и новые коммуникативные практики: опыт трансформации}

Пандемия явилась на протяжении весны главным информационным поводом для всех без исключения медийных и офлайн-коммуникативных платформ. Применительно к нацпроектам ситуация свела обсуждение к их возможному срыву или секвестированию ${ }^{3}$. Это еще больше подорвало доверие населения к возможности реализации нацпроектов. Во время пандемии появился большой объем фейковой информации, медиасфера патологически разрослась, многочисленные адресаты стали авторами, и на фоне этого масштабного информационного шума стала очевидной необходимость использования новых коммуникативных практик. Коронавирус во всем мире предоставил многим гражданам возможность реализовать себя как медиа, усилить общественный контроль над правительствами со стороны медиасообществ и продемонстрировал важность краудсорсинговых платформ.

\section{Заключение}

Основная идея улучшения информационного и организационного сопровождения нацпроектов сегодня связана, во-первых, с возникновением специализированных ресурсов в социальных медиа, специализированных СМИ и на новых медийных платформах и, во-вторых, с вовлечением в создание контента целевых аудиторий (прежде всего молодежи).

Такой многоканальный подход позволит сегментировать продвижение проектов к заинтересованной целевой аудитории, а также вовлечь аудиторию (преимущественно это касается молодежи) в соучастие, хотя бы медийное.

Перспективным представляется также создание единого информационного peсурса, который бы использовал технологии big data для анализа хода выполнения нацпроектов и репрезентации этих данных в удобной инфографике.

\footnotetext{
1 Исследование аудитории Telegram 2019. Доступ: https://tgstat.ru/research (проверено 01.05.2020).

2 Валерий Федоров: Телеграм-каналы заменили россиянам советские кухни. - ВЦИОМ. Доступ: https://wciom.ru/index.php?id =238\&uid=9774 (проверено 01.05.2020).

3 Меры по борьбе с коронавирусом могут привести к срыву национального проекта «Здравоохранение». - Эхо Москвы. 30.04.2020. Доступ: https://echo.msk.ru/news/2634809-echo.html (проверено 15.05.2020).
} 
Важное место должен занимать разбор результатов прошлой волны проектов. Такая транспарентность была бы лучшей формой продвижения проектов для ныне недоверчивой аудитории. Самая же большая опасность в продвижении возврат к советской методике и риторике «пятилеток».

Статья подготовлена по результатам исследований, выполненныхзасчет бюджетныхсредств погосударственному заданию Финуниверситету.

\title{
Список литературы
}

Домбровская А.Ю., Пырма Р.В., Батанина И.А. 2019. Профессиональные стратегии российской молодежи в условиях цифровизации и их репрезентация в социальных медиа: результаты комплексного прикладного анализа. Мониторинг общественного мнения: Экономические и социальные перемены. № 5. C. 162-182.

Епишкин И.И., Исакова Е.Б., Лаврик А.А. 2019. Анализ интересов и предпочтений российской аудитории социальной сети TikTok. Вестник Московского гуманитарно-экономического института. № 4. С. 62-67.

Каминская Т.Л., Помигуев И.А., Назарова Н.А. 2019. Экологический активизм в цифровой среде как инструмент влияния на государственные решения. - Мониторинг общественного мнения: экономические и социальные перемены. № 5. C. 382-407.

Кожевников С.А. 2020. Проблемы развития проектного управления в публичном секторе в ракурсе достижения национальных целей - Проблемы развития территории. № 1(105). С. 64-77.

Шомова С.А. 2019. Выборы президента РФ - 2018 в зеркале мемов: новые реалии политической коммуникативистики. - Полис. Политические исследования. № 3. С. 157-173.

KAMINSKAYA Tatyana Leonidovna, Dr.Sci. (Philol.), Associate Professor; Professor of the Departmentof Political Science and Mass Communications, Financial University under the Government of the Russian Federation (49 Leningradsky Ave, Moscow, Russia, 125993; tlkam1@mail.ru)

CHAUSOV Aleksandr Igorevich, Cand.Sci. (Hist.), Associate Professor; Associate Professor of the Chair of Journalism, Novgorod State University (41 St. Petersburgskaya St, Veliky Novgorod, Russia, 173003; aleshausov@mail.ru)

\section{NATIONAL PROJECTS AND MEDIA: PROMOTION AND PERCEPTION}

\begin{abstract}
The article presents the results of monitoring of information on national projects of Russia in the Russianspeaking media sphere: in federal information projects, in leading media, social networks and messengers, as well as in new media formats. The relevance of the study is due to the fact that the implementation of national projects largely depends on the population's perception of long-term power plans and peopless involvement in monitoring and discussing their implementation.

The authors show how unevenly various national projects in the media sphere are represented, what perceptual features are associated with them. Content analysis of media resources shows that a positive news agenda is much more difficult to promote in popular new media formats. The article sees the prospects for the effective promotion of national projects by author's channels in messengers and involving the population in communication in media formats. It is also promising to create a unified information resource that would use the big data technology to analyze the progress of national projects and represent this data in a convenient infographics.
\end{abstract}

Keywords: national projects, media, target audience, social networks, new media formats 